\title{
Management of deltoid ligament injuries in acute ankle fracture: a systematic review
}

\author{
Michael James, MD \\ Andrew Dodd, MD
}

Accepted Feb. 4, 2021

\author{
Correspondence to: \\ M. James \\ Department of Surgery \\ University of Calgary \\ 3330 Hospital Dr NW \\ Calgary AB T2N 4N1 \\ michael.james@ahs.ca
}

Cite as: Can J Surg 2022 January 11; 65(1). doi: $10.1503 /$ cjs. 020320
Background: Deltoid ligament repair (DLR) was historically a common adjunct to ankle fracture fixation; however, prevailing clinical practice is to explore the medial side of the ankle only if reduction is blocked. We performed a systematic review to determine the breadth and quality of the literature evaluating DLR in the context of ankle fractures.

Methods: We searched the MEDLINE and Embase databases in May 2020 for English-language articles evaluating DLR versus no repair or syndesmotic fixation in patients with acute ankle fractures. We used descriptive statistics to compare studies and draw conclusions.

Results: Of 362 articles identified, 8 (3 randomized controlled trials [RCTs] and 5 retrospective cohort studies) were included in our final analysis. Five studies compared DLR to conservative management, and 3 compared DLR to transsyndesmotic fixation. Functional outcomes were equivalent between groups. Five of the 6 studies that included radiographic outcomes showed a statistically significant decrease in the medial clear space and decreased malreduction rates postoperatively in the DLR groups.

Conclusion: High-quality evidence guiding treatment of deltoid ligament injury in acute ankle fractures is lacking; currently available evidence appears to support DLR. Given recent increased interest in DLR and syndesmotic fixation, a comprehensive multicentre RCT is warranted. Although radiographic evidence indicates the potential benefit of DLR, further research is required to establish the superiority of DLR versus clinical equipoise.

Contexte : De tout temps, la réparation du ligament deltoïde (RLD) a fait partie de la fixation des fractures de la cheville; toutefois, la pratique clinique qui a cours actuellement consiste à n'explorer le côté médial de la cheville que si la réduction se trouve bloquée. Nous avons procédé à une revue systématique afin de déterminer l'étendue et la qualité de la littérature sur la RLD dans le contexte de la fracture de la cheville.

Méthodes: Nous avons interrogé les bases de données MEDLINE et Embase en mai 2020 pour recenser les articles de langue anglaise portant sur la RLD c. absence de réparation ou fixation syndesmotique chez des patients atteints d'une fracture aiguë de la cheville. Nous avons utilisé les statistiques descriptives pour comparer les études et tirer des conclusions.

Résultats : Sur les 362 articles recensés, 8 ont été inclus dans notre analyse finale (3 sur des essais randomisés et contrôlés [ERC] et 5 sur des études de cohorte rétrospective). Cinq études ont comparé la RLD au traitement conservateur, et 3 l'ont comparée à la fixation transsyndesmotique. Les résultats fonctionnels ont été équivalents entre les groupes. Cinq études sur 6 qui incluaient des résultats radiographiques ont montré une diminution statistiquement significative de l'espace clair médial, et des taux moindres de malréduction postopératoire dans les groupes soumis à la RLD.

Conclusion : Il manque de données probantes de grande qualité pour guider le traitement des lésions au ligament deltoïde qui accompagnent les fractures aiguës de la cheville; les données actuellement disponibles semblent appuyer la RLD. Compte tenu du récent regain d'intérêt pour la RLD et la fixation syndesmotique, la réalisation d'un ERC multicentrique complet s'impose. Même si les résultats radiographiques témoignent du bienfait potentiel de la RLD, il faut approfondir la recherche pour en confirmer la supériorité par rapport à l'incertitude clinique actuelle. 
A nkle fractures are one of the most common injuries encountered in orthopedic practice. Damage to ankle ligaments often occurs concomitant with bony injury $^{1}$ and, when left unaddressed, can lead to chronic ankle instability and accelerated posttraumatic arthritis. ${ }^{2}$ Much attention has been devoted in the literature to syndesmotic ligaments on the lateral aspect of the ankle; however, the deltoid ligament has received considerably less attention.

The deltoid ligament is a medial ankle structure consisting of the superficial deltoid (superficial posterior tibiotalar, tibiospring, tibiocalcaneal and tibionavicular ligaments) and deep deltoid (deep anterior and posterior tibiotalar ligaments). ${ }^{3}$ The primary function of the superficial deltoid is to resist hindfoot eversion, whereas the primary function of the deep deltoid is to resist external rotation of the talus relative to the tibia. ${ }^{2}$ Thus, the deltoid ligament is vital in maintaining overall ankle stability and congruent force distribution in the ankle mortise. Indications of deltoid ligament injury include medial clear space (MCS) greater than $5 \mathrm{~mm}$ on external rotation or gravity stress radiographs. ${ }^{4}$

Deltoid ligament repair (DLR) was historically a common adjunct to ankle fracture fixation. Nevertheless, the prevailing clinical practice is to explore the medial side of the ankle only if there is a block to reduction. ${ }^{2}$ Deltoid ligament repair is controversial; some surgeons believe that deltoid ligament integrity is vital to long-term ankle stability, ${ }^{5}$ whereas others regard DLR as a time-consuming endeavour of little to no clinical benefit. ${ }^{6,7}$

Deltoid ligament repair can be performed safely, efficiently and cost-effectively with modern techniques. Thus, if DLR is beneficial, particularly in a younger, more active patient population, it is an important operative adjunct to consider. In addition, if DLR can offer better stability and a more accurate reduction than syndesmotic fixation, this obviates the need for implant removal, which is sometimes associated with rigid syndesmotic fixation.

We performed a systematic review with the primary aim of determining the breadth and quality of the literature evaluating DLR in the context of ankle fractures.

\section{Methods}

We conducted a systematic review of the English-language literature in accordance with the Preferred Reporting Items for Systematic review and Meta-Analysis Protocols (PRISMA-P) guidelines. ${ }^{8}$

To identify relevant studies, we used the Ovid search engine to search the Embase and MEDLINE electronic databases. We performed the search on May 23, 2020, using the following strategy: MEDLINE: (deltoid ligament $^{*}$.ti.kf.) search for deltoid ligament(s) in the title or author-supplied keyword fields; Embase: (deltoid liga-

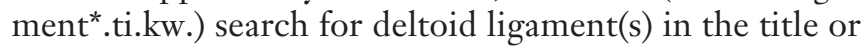
author-supplied keyword fields. We also searched refer- ences of the final selected studies for relevant articles to reduce the likelihood of omitting pertinent articles.

We included studies focusing on DLR in the context of acute ankle fractures, studies whose population comprised more than $50 \%$ adult ( $>18 \mathrm{yr}$ of age) patients and studies that included more than 5 patients. We excluded reviews, technical papers, radiographic assessments of deltoid ligament integrity, studies of repairs for chronic deltoid ligament insufficiency, studies in languages other than English and studies lacking a comparison group.

\section{Study selection}

The authors independently conducted the systematic review. Results from all databases were combined, and non-English-language titles and duplicates were removed. Both authors assessed the articles at each stage of the filtering process (titles, abstracts and full-length articles). At all stages except for the final stage, disagreement led to inclusion. At the final stage of selection, disagreement was resolved by consensus.

\section{Data extraction}

After the final selection of full-length articles, 1 author (M.J.) performed data extraction. Basic data, including the title, year of publication, journal title, number of patients in each cohort, type of study and level of evidence, were extracted. The following specific data were also collected: follow-up duration, assessment of deltoid ligament integrity, repair technique, syndesmosis treatment, functional and radiographic outcomes, and authors' conclusions.

\section{Data analysis}

The heterogeneity of the included studies precluded true statistical meta-analysis. Thus, we used descriptive statistics to compare studies and draw conclusions.

\section{REsults}

Of 362 articles identified, 8 (3 randomized controlled trials [RCTs] and 5 retrospective cohort studies) were selected for inclusion in the final analysis (Figure 1). Five studies compared DLR to no repair, and 3 studies compared DLR to transsyndesmotic fixation at the time of fracture fixation. One study was published in 1995, and the rest were published between 2015 and 2018. Overall, 403 ankles were reviewed. The average duration of follow-up was 31 (range 12-60) months (Table 1).

Deltoid ligament injury was diagnosed by preoperative or intraoperative MCS measurements; in 2 studies, preoperative magnetic resonance imaging was also performed. The predominant method for DLR was suture anchor fixation (Table 2). 


\section{Studies comparing deltoid ligament repair versus no repair}

The earliest study, carried out by Strömsöe and colleagues, ${ }^{7}$ was an RCT in which 25 patients with Weber B or C fibula fractures were randomly allocated to DLR with fibula open reduction and internal fixation (ORIF), and 25 patients to fibula ORIF alone. Thirty-nine patients (19 in the DLR group and 20 in the no-repair group) were observed to have ruptured syndesmosis, but it was not

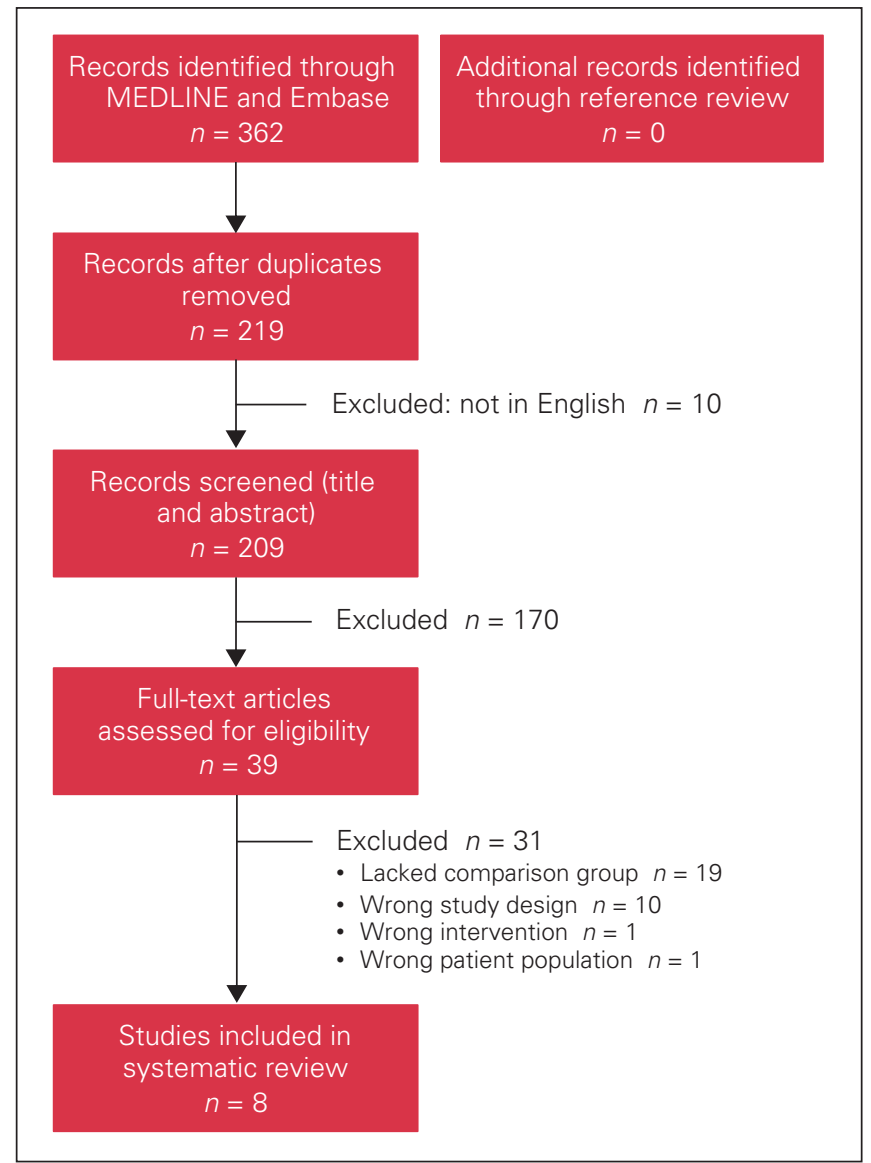

Fig. 1. Flow diagram showing study selection. specified which of these patients underwent syndesmotic fixation. The authors focused on the qualitative assessment of mortise congruency to establish adequate reductions both intraoperatively and postoperatively. After an average follow-up duration of 17 months, both groups maintained a congruent mortise. No between-group differences in working ability, sports activities engaged in, pain, swelling, metal removed or overall movement were observed. Deltoid ligament repair was associated with significantly longer operative time $(75 \mathrm{~min}$ v. $95 \mathrm{~min} ; p=0.04)$. The authors concluded that DLR was superfluous if a congruent mortise could be established intraoperatively.

$\mathrm{Gu}$ and colleagues ${ }^{9}$ conducted an RCT that included 40 patients with ankle fractures and deltoid ligament injury, as indicated by preoperative magnetic resonance imaging and MCS greater than $5 \mathrm{~mm}$ on preoperative stress radiographs. They randomly allocated 20 patients to fibula ORIF alone and 20 to ORIF plus DLR with suture anchors. After follow-up of 12-18 months, the DLR group showed better American Orthopaedic Foot and Ankle Society (AOFAS) scores $(p=0.001)$, decreased pain scores (as assessed on a visual analogue scale) $(p=0.02)$ and a reduction in MCS compared to preoperative values $(p=$ 0.02 ). The no-repair group had a mean operative time of 88.5 minutes, mean blood loss of $276 \mathrm{~mL}$ and mean length of stay of 17.6 days, compared to 158.5 minutes, $385.5 \mathrm{~mL}$ (estimated) and 10.4 days, respectively, for the DLR group. The authors concluded that DLR offers improved ankle function, reduced pain and a "remarkable curative effect" in the management of ankle fractures with deltoid ligament injury.

Zhao and colleagues ${ }^{10}$ retrospectively reviewed the cases of 74 patients who had Weber B or C fractures with MCS greater than $6 \mathrm{~mm}$. Twenty patients underwent fibula ORIF plus DLR with suture anchors, and 54 patients underwent fibula ORIF alone. No functional between-group differences were observed after an average follow-up duration of 53.7 months. The authors noted a decreased rate of malreduction (defined as postoperative MCS $>5 \mathrm{~mm}$ ) in the DLR group than in the

\begin{tabular}{|c|c|c|c|}
\hline Study & Level of evidence & Comparison groups (no. of ankles) & Average length of follow-up, mo \\
\hline Strömsöe et al., ${ }^{7} 1995$ & । & DLR (25) v. no repair (25) & 17 \\
\hline Little et al., ${ }^{6} 2015$ & III & $\begin{array}{l}\text { DLR + PITFL repair (27) v. syndesmotic fixation } \\
\text { (18) }\end{array}$ & Minimum of 12 \\
\hline Jones et al., ${ }^{12} 2015$ & III & DLR (12) v. syndesmotic fixation (15) & Syndesmotic 60.8, DLR 77.6 \\
\hline Gu et al., ${ }^{9} 2017$ & 1 & DLR (20) v. no repair (20) & $12-18$ \\
\hline Zhao et al.., ${ }^{10} 2017$ & III & DLR (20) v. no repair (54) & 53.7 \\
\hline Woo et al., ${ }^{1} 2018$ & III & DLR (41) v. no repair (37) & 17 \\
\hline Wu et al., ${ }^{13} 2018$ & I & DLR (22) v. syndesmotic fixation (26) & 22.7 \\
\hline Sun et al., ${ }^{11} 2018$ & III & $\begin{array}{l}\text { Superficial DLR (12) v. superficial and deep } \\
\text { DLR (16) v. no repair (13) }\end{array}$ & 41.7 \\
\hline
\end{tabular}




\begin{tabular}{|c|c|c|c|c|}
\hline Study & $\begin{array}{l}\text { Diagnostic criteria for deltoid ligament } \\
\text { injury }\end{array}$ & Method for DLR & $\begin{array}{l}\text { Management of posterior } \\
\text { malleolus }\end{array}$ & $\begin{array}{l}\text { Management of syndesmosis } \\
\text { (no. of ankles) }\end{array}$ \\
\hline Strömsöe et al. ${ }^{7}$ & $\begin{array}{l}\text { Difference of }>3 \mathrm{~mm} \text { in MCS compared } \\
\text { to contralateral ankle on anteroposterior } \\
\text { unstressed radiographs }\end{array}$ & Suture repair & Not specified & $\begin{array}{l}\text { Syndesmotic screw (no-repair } \\
\text { group 20, DLR group 19) }\end{array}$ \\
\hline Little et al. ${ }^{6}$ & $\begin{array}{l}\text { - Preoperative MRI } \\
\text { - Intraoperative MCS > } 5 \mathrm{~mm} \text { on external } \\
\text { rotation stress radiographs }\end{array}$ & Suture anchors & Excluded & $\begin{array}{l}\text { - Syndesmotic screw in } \\
\text { syndesmotic group } \\
\text { - No syndesmotic fixation in } \\
\text { DLR group }\end{array}$ \\
\hline Jones et al. ${ }^{12}$ & $\begin{array}{l}\text { MCS }>5 \mathrm{~mm} \text { on preoperative gravity or } \\
\text { external rotation stress radiographs }\end{array}$ & Suture anchors & Excluded & $\begin{array}{l}\text { - Syndesmotic implant in } \\
\text { syndesmotic group } \\
\text { - No syndesmotic implant in } \\
\text { DLR group }\end{array}$ \\
\hline Gu et al. ${ }^{9}$ & $\begin{array}{l}\text { - Preoperative MRI } \\
\text { - MCS }>5 \mathrm{~mm} \text { on preoperative stress } \\
\text { radiographs }\end{array}$ & Suture anchors & $\begin{array}{l}\text { - }>25 \% \text { of articular } \\
\text { surface: excluded } \\
\text { - } \leq 25 \% \text { of articular } \\
\text { surface: included, not } \\
\text { fixed }\end{array}$ & Unspecified in both groups \\
\hline Zhao et al. ${ }^{10}$ & $\begin{array}{l}\text { MCS }>6 \mathrm{~mm} \text { on preoperative } \\
\text { anteroposterior unstressed radiographs }\end{array}$ & Suture anchors & ORIF & $\begin{array}{l}\text { Syndesmotic screw (no-repair } \\
\text { group 21, DLR group 9) }\end{array}$ \\
\hline Woo et al. ${ }^{1}$ & $\begin{array}{l}\text { MCS }>4 \mathrm{~mm} \text { or difference of }>1 \mathrm{~mm} \\
\text { between MCS and superior joint space } \\
\text { on intraoperative gravity stress views }\end{array}$ & Suture anchors & Not specified & $\begin{array}{l}\text { 1-2 syndesmotic screws } \\
\text { (no-repair group 17, DLR group } \\
\text { 27) }\end{array}$ \\
\hline Wu et al. ${ }^{13}$ & $\begin{array}{l}\text { - Intraoperative "tap test" } \\
\text { - Exploration of deltoid ligaments }\end{array}$ & $\begin{array}{l}\text { - Middle third: interrupted } \\
\text { sutures } \\
\text { - Proximal avulsion: suture } \\
\text { anchors } \\
\text { - Distal avulsion: suture } \\
\text { anchors into talus, } \\
\text { threaded through drill holes } \\
\text { in medial malleolus }\end{array}$ & ORIF & $\begin{array}{l}\text { - Syndesmotic screw in } \\
\text { transsyndesmotic group } \\
\text { - No fixation in DLR group }\end{array}$ \\
\hline Sun et al. ${ }^{11}$ & $\begin{array}{l}\text { Intraoperative valgus and external rotation } \\
\text { stress resulting in MCS twice that of } \\
\text { contralateral ankle }\end{array}$ & $\begin{array}{l}\text { - Superficial: suture anchor } \\
\text { into distal tibia } \\
\text { - Deep: suture anchor into } \\
\text { talus, passing through drill } \\
\text { holes in medial malleolus }\end{array}$ & Not specified & $\begin{array}{l}1-2 \text { tricortical syndesmotic } \\
\text { screws* }\end{array}$ \\
\hline
\end{tabular}

no-repair group ( $0 \%$ v. $20.4 \%$; $p=0.03$ ), a phenomenon that was more pronounced in patients with Weber C fractures. The authors concluded that DLR decreases ankle mortise malreduction, particularly in Weber C fractures. Management of syndesmotic injury was not explicitly addressed.

Woo and colleagues ${ }^{1}$ retrospectively reviewed 78 cases of supination and pronation external rotation ankle fracture associated with deltoid ligament injury. Diagnosis of deltoid ligament injury was based on intraoperative gravity stress views showing the MCS to be greater than $4 \mathrm{~mm}$ or a difference of more than $1 \mathrm{~mm}$ between the MCS and the superior joint space. Forty-one patients underwent fibula ORIF with DLR, and 37 patients underwent fibula ORIF alone. After an average follow-up duration of 17 months, no difference in functional outcomes was noted between the 2 groups. However, a subset analysis of those who underwent syndesmotic fixation showed significantly better AOFAS and Foot Function Index scores, and significantly lower visual analogue scale pain scores and medial-sided pain in the DLR group. A decreased MCS was noted at final follow-up in the DLR group overall $(3.2 \mathrm{~mm} \mathrm{v}$. $3.7 \mathrm{~mm}$ in the no-repair group; $p<0.001)$. Woo and colleagues ${ }^{1}$ concluded that DLR may be a beneficial adjunct to fibula ORIF, especially in the context of concomitant syndesmotic injury.

Sun and colleagues ${ }^{11}$ conducted a prospective cohort study involving 41 Weber B ankle fractures with suspected deltoid ligament injury. Diagnosis of deltoid ligament injury was based on intraoperative valgus and external rotation stress resulting in an MCS twice that of the contralateral ankle. Patients were treated with fibula ORIF alone $(n=13)$, ORIF with superficial deltoid repair $(n=12)$ or ORIF with superficial and deep deltoid repair $(n=16)$. The average length of follow-up was 41.7 months. No significant differences in functional outcomes or radiologic measures (perpendicular or oblique MCS) were noted at any time point. The authors concluded that deltoid ligament exposure and repair are unnecessary adjuncts to fracture fixation. 


\section{Studies comparing deltoid ligament repair versus syndesmotic fixation}

Little and colleagues ${ }^{6}$ performed a retrospective analysis of bimalleolar-equivalent ankle fractures (fibula fracture with deltoid ligament rupture). Diagnosis of deltoid ligament injury was based on preoperative magnetic resonance imaging and intraoperative MCS greater than $5 \mathrm{~mm}$ on external rotation stress views. The authors compared 18 patients who underwent fibula ORIF and transsyndesmotic screw placement to 27 patients treated with an "anatomic" repair technique that involved fibula ORIF with deltoid and posterior inferior tibiofibular ligament repair. The primary outcome was syndesmotic malreduction, evaluated on computed tomography. No standardized functional outcome measures were reported. After followup for a minimum of 12 months, there was a lower rate of syndesmotic malreduction in the anatomic treatment group than in the transsyndesmotic fixation group $(7.4 \% \mathrm{v}$. $33.3 \% ; p=0.02$ ), as well as a higher frequency of secondary surgery for implant removal in the transsyndesmotic fixation group (14 v. 3). The authors concluded that more studies are required to assess the clinical importance of the radiographic decrease in malreduction observed with the anatomic repair technique.

Jones and Nunley ${ }^{12}$ retrospectively reviewed the cases of 27 bimalleolar-equivalent ankle fractures, as determined by an MCS greater than $5 \mathrm{~mm}$ on preoperative gravity or external rotation stress radiographs. Fifteen patients were treated with transsyndesmotic fixation, and 12 were treated with DLR without syndesmotic fixation. After an average follow-up duration of 60.8 months in the syndesmotic fixation group and 77.6 months in the DLR group, no difference in any functional outcome measure was observed. Maintenance of an anatomic ankle mortise reduction with no signs of arthritis was noted in $93 \%$ of patients in the syndesmotic fixation group and $100 \%$ of those in the DLR group. However, no quantitative radiographic outcomes were reported. The authors concluded that the 2 fixation techniques were functionally equivalent but that DLR obviates the need for implant removal.

Finally, $\mathrm{Wu}$ and colleagues ${ }^{13}$ compared transsyndesmotic fixation to DLR for bimalleolar-equivalent ankle fracture while also investigating the utility of an intraoperative "tap" test for diagnosing deltoid ligament injury. The tap test was introduced in 2010 by Rajagopalan and colleagues $^{14}$ to identify syndesmotic injury based on the principle of converting the force of tapping into syndesmotic diastasis. Deltoid ligament injury was determined by intraoperative exploration of the deltoid ligaments as well as by the tap test. Twenty-two patients underwent fibula ORIF with DLR, and 26 underwent fibula ORIF with transsyndesmotic screw fixation. The DLR technique differed according to injury location: middle third tears were treated with interrupted suture repair, proximal avulsions were treated with suture anchor fixation, and distal avulsions were treated by placement of suture anchors into the talus, threaded through drill holes in the medial malleolus. After follow-up for an average of 22.7 months, no significant between-group differences in functional outcomes were noted. The rate of syndesmotic malreduction on postoperative bilateral computed tomography was significantly lower in the DLR group than in the syndesmosis screw group $(9.1 \%$ v. $34.6 \% ; p=0.04)$. In addition to validating the tap test for the identification of deltoid ligament injury, $\mathrm{Wu}$ and colleagues ${ }^{13}$ concluded that DLR gives comparable functional outcomes and improved syndesmotic reduction when compared to transsyndesmotic fixation.

\section{Functional outcomes}

Standardized functional outcomes were reported in 6 studies. The AOFAS and visual analogue scale pain scores were the most commonly reported functional outcome measures. Strömsöe and colleagues ${ }^{7}$ used their own outcome measures, and Little and colleagues ${ }^{6}$ did not report any functional outcomes. Gu and colleagues ${ }^{9}$ reported statistically significant improvements in pain and AOFAS scores in the DLR group. Functional outcomes were equivalent between groups in the 6 remaining studies (Table 3).

\section{Radiographic outcomes}

Quantifiable radiographic outcomes were reported in 6 studies. Strömsöe and colleagues ${ }^{7}$ did not include any radiographic outcomes, and Jones and Nunley ${ }^{12}$ commented only on the "maintenance of an anatomic ankle mortise" and "signs of arthritis." Five studies reporting quantifiable radiographic outcomes showed a statistically significant decrease in postoperative MCS or decreased rate of syndesmotic malreduction, or both, with DLR compared to no repair or syndesmotic fixation (Table 3).

\section{Complications}

Complications reported beyond malreduction or removal of hardware were mainly limited to wound complications: overall, 11 wound infections were reported, 4 in the DLR groups and 7 in the no-repair groups. One infection in the DLR group was noted to be major, and the remainder of the infections were deemed superficial or severity was not specified. None of the authors specified whether the infections occurred on the medial or lateral side in the DLR cohorts.

\section{Discussion}

Our systematic review shows that there exists a paucity of high-quality evidence guiding the treatment of deltoid 
Table 3. Summary of radiographic and functional outcomes

\begin{tabular}{|c|c|c|}
\hline Study & Radiographic outcomes & Functional outcomes \\
\hline Strömsöe et al. ${ }^{7}$ & None reported & No difference \\
\hline Little et al. ${ }^{6}$ & $\begin{array}{l}\text { Higher rate of syndesmotic malreduction in syndesmotic group v. "anatomic" } \\
\text { repair group }(33.3 \% \text { v. } 7.4 \% ; p<0.02)\end{array}$ & None reported \\
\hline Jones et al..$^{12}$ & No quantifiable radiographic outcomes reported & No difference \\
\hline Gu et al. ${ }^{9}$ & $\begin{array}{l}\text { Postoperative MCS decreased in DLR group v. no-repair group }(2.1 \mathrm{~mm} \\
\text { v. } 2.8 \mathrm{~mm} ; p=0.01)\end{array}$ & $\begin{array}{l}\text { - Decreased VAS scores at } 3 \text { mo in DLR group } \\
\text { - Improved AOFAS scores at all time points in DLR } \\
\text { group }\end{array}$ \\
\hline Zhao et al. ${ }^{10}$ & $\begin{array}{l}\text { - MCS decreased in DLR group v. no-repair group immediately after operation } \\
\text { (3.3 mm v. } 3.8 \mathrm{~mm} ; p=0.03 \text { ) and at final follow-up ( } 3.2 \mathrm{~mm} \mathrm{v.} 3.8 \mathrm{~mm} ; p= \\
\text { 0.03) } \\
\text { - Rate of mortise malreduction greater in no-repair group v. DLR group }(20.4 \% \\
\text { v. } 0 \% ; p=0.03)\end{array}$ & No difference \\
\hline Woo et al. ${ }^{1}$ & $\begin{array}{l}\text { MCS decreased in DLR group v. no-repair group at final follow-up }(3.2 \mathrm{~mm} \\
\text { v. } 3.7 \mathrm{~mm} ; p<0.001 \text { ) }\end{array}$ & $\begin{array}{l}\text { In subanalysis, increased AOFAS and FFI scores, and } \\
\text { decreased VAS pain scores and medial-sided pain } \\
\text { favouring DLR and syndesmotic fixation over } \\
\text { syndesmotic fixation alone }\end{array}$ \\
\hline Wu et al. ${ }^{13}$ & $\begin{array}{l}\text { Increased rate of mortise malreduction in transsyndesmotic group } v \text {. DLR group } \\
(34.6 \% \text { v. } 9.1 \% ; p=0.04)\end{array}$ & No difference \\
\hline Sun et al. ${ }^{11}$ & No difference in oblique or perpendicular MCS postoperatively & No difference \\
\hline
\end{tabular}

ligament injury in acute ankle fractures. Furthermore, the heterogeneity in the methodology and outcome measures of our selected studies precluded a meaningful metaanalysis of results. However, various trends can be inferred from the qualitative analysis of the studies.

Although functional outcomes were equivalent between groups overall, current foot and ankle functional outcome measures are sensitive only to large differences in overall function and quality of life. Thus, more subtle yet clinically relevant disparities in outcomes, including proprioception, and ankle mobility and instability, are underrecognized. These outcomes are particularly important in younger, more athletic populations, who require optimal ankle function. It is possible that our current outcome instruments miss these meaningful differences.

The average follow-up time in our selected studies was 31 months. Day and colleagues ${ }^{15}$ showed that the poor radiographic outcomes seen in short-term ankle fracture followup do in fact correlate with worse functional outcomes when follow-up is extended to 10 or more years. Thus, an average of 31 months of follow-up is clearly inadequate to fully assess long-term ankle function. Considering the lack of adequate follow-up, we must rely on radiographic measures as surrogates for long-term ankle function. The association between articular malreduction and posttraumatic arthritis is well established ${ }^{16}$ although there are several contributing factors that preclude a perfect correlation. Nonetheless, most of the studies showed that DLR led to improved radiographic ankle reduction, thus pointing to the potential long-term benefit of DLR. Given the challenge of running longitudinal studies for up to 10 years, computer modelling, such as of the impact of deltoid ligament injury on ankle biomechanics and load distribution, in the form of finite element analysis may be able to help answer some of these questions.
Although several studies showed improved radiographic outcomes in the DLR group, the RCT by Gu and colleagues, ${ }^{9}$ which provided the strongest overall support for DLR, had questionable rigour. Those authors reported an additional 70 minutes of operative time for DLR and hospital stays averaging about 14 days for ankle fracture. These values are important outliers, as DLR typically adds less than 30 minutes of operative time, and hospital stays beyond 48-72 hours for isolated ankle fracture are rare. These disparities, as well as several other errors in the article, point to a lack of methodologic rigour and bring into question their strong support for DLR. Still, the disparity in operating time, as well as the potential for increased wound complications when performing DLR, are valid considerations. Many of our selected articles did not address discrepancies in operative time, and none explicitly addressed the location (medial or lateral) of wound complications. This ultimately precluded a valid comparison of potential risks of DLR.

Overall, our results are in agreement with those of a systematic review by Dabash and colleagues ${ }^{17}$ and a review by Lee and colleagues, ${ }^{2}$ both of which showed a paucity of strong support for or against DLR. However, the reviews did not include studies comparing DLR to syndesmotic fixation. One of the strengths of our review is that we identified and included 3 such studies. The importance of the complex interplay between syndesmotic ligaments and the deltoid ligament should not be overlooked. The current literature often looks at injuries to these structures independently. This simplification, although helpful for research purposes, runs the risk of overlooking the impact of combined injuries. It is common for the deltoid and syndesmotic ligaments to be disrupted concomitantly; therefore, their treatments should not be examined in isolation. 
With a heavy emphasis on the importance of syndesmotic reduction in the recent literature, ${ }^{18}$ it is interesting to see that DLR had a considerable impact on syndesmosis reduction in the papers reviewed here. Future research should further examine the relation between deltoid and syndesmotic ligament injuries and treatments.

\section{Limitations}

A weakness of our study is the lack of quantitative data. Rather than relying on known associations between malreduction and posttraumatic arthritis, an appropriate solution would be a sufficiently powered RCT with long-term follow-up. Given the daunting logistics, alternative research designs have been used. Butler and colleagues ${ }^{19}$ reported that fibula ORIF with DLR in a cadaveric model restored ankle stability to that of an intact ankle; conversely, fibula ORIF without DLR was associated with considerable translational and rotational instability. Similarly, Goetz and colleagues ${ }^{20}$ showed that both DLR with anterior inferior tibiofibular ligament repair and rigid syndesmotic screw fixation in a cadaveric model led to considerably better syndesmotic reduction than flexible syndesmotic fixation techniques, such as suture button and suture tape augmentation techniques. Although these studies are methodologically sound, biomechanical studies are far less likely to alter clinical paradigms than a large RCT. Considering the resurgence of interest in DLR, now may be the time to conduct a well-designed multicentre RCT.

\section{Conclusion}

Although radiographic evidence points to the potential benefit of DLR in the context of acute ankle fracture, further research is required to establish the superiority of DLR versus clinical equipoise. This research should focus on all components of ankle injuries, including fracture fixation, management of deltoid ligament and posterior malleolus injuries, and treatment for syndesmosis disruption. Further investigation on this topic is particularly important given the ubiquity of ankle fractures and the potential long-term sequelae of these injuries.

Affiliations: From the Department of Surgery, University of Calgary, Calgary, Alta. (James); and the Foothills Medical Centre, Calgary, Alta. (Dodd).

Competing interests: None declared.

Contributors: Both authors designed the study. Both authors acquired and analyzed the data and wrote the manuscript, which A. Dodd critically revised. Both authors gave final approval of the article to be published.

Content licence: This is an Open Access article distributed in accordance with the terms of the Creative Commons Attribution (CC BYNC-ND 4.0) licence, which permits use, distribution and reproduction in any medium, provided that the original publication is properly cited, the use is noncommercial (i.e., research or educational use), and no modifications or adaptations are made. See: https://creativecommons. org/licenses/by-nc-nd/4.0/.
Funding: The authors received no financial support for the research, authorship or publication of this article.

\section{References}

1. Woo SH, Bae SY, Chung HJ. Short-term results of a ruptured deltoid ligament repair during an acute ankle fracture fixation. Foot Ankle Int 2018;39:35-45.

2. Lee S, Lin J, Hamid KS, et al. Deltoid ligament rupture in ankle fracture: diagnosis and management. 7 Am Acad Orthop Surg 2019;27: e648-58.

3. Lee TH, Jang KS, Choi GW, et al. The contribution of anterior deltoid ligament to ankle stability in isolated lateral malleolar fractures. Injury 2016;47:1581-5.

4. Stufkens SAS, van den Bekerom MPJ, Knupp M, et al. The diagnosis and treatment of deltoid ligament lesions in supination-external rotation ankle fractures: a review. Strateg Trauma Limb Reconstr 2012;7: $73-85$.

5. Harper MC. The deltoid ligament. An evaluation of need for surgical repair. Clin Orthop Relat Res 1988;(226):156-68.

6. Little MM, Berkes MB, Schottel PC, et al. Anatomic fixation of supination external rotation type IV equivalent ankle fractures. 7 Orthop Trauma 2015;29:250-5.

7. Strömsöe K, Höqevold HE, Skjeldal S, et al. The repair of a ruptured deltoid ligament is not necessary in ankle fractures. 7 Bone foint Surg Br 1995;77:920-1.

8. Moher D, Shamseer L, Clarke M, et al.; PRISMA-P Group. Preferred Reporting Items for Systematic review and Meta-Analysis Protocols (PRISMA-P) 2015 statement. Syst Rev 2015;4:1.

9. Gu G, Yu J, Huo Y, et al. Efficacy of deltoid ligament reconstruction on the curative effect, complication and long-term prognosis in ankle fracture-dislocation with deltoid ligament injury. Int $\mathcal{F}$ Clin Exp Med 2017;10:13778-83.

10. Zhao HM, Lu J, Zhang F, et al. Surgical treatment of ankle fracture with or without deltoid ligament repair: a comparative study. $B M C$ Musculoskelet Disord 2017;18:543.

11. Sun $X, L_{i} T$, Sun $Z$, et al. Does routinely repairing deltoid ligament injuries in type B ankle joint fractures influence long term outcomes? Injury 2018;49:2312-7.

12. Jones CR, Nunley JA. Deltoid ligament repair versus syndesmotic fixation in bimalleolar equivalent ankle fractures. 7 Orthop Trauma 2015;29:245-9.

13. Wu K, Lin J, Huang J, et al. Evaluation of transsyndesmotic fixation and primary deltoid ligament repair in ankle fractures with suspected combined deltoid ligament injury. 7 Foot Ankle Surg 2018;57:694700 .

14. Rajagopalan S, Upadhyay V, Taylor HP, et al. New intra-operative technique for testing the distal tibiofibular syndesmosis. Ann $R$ Coll Surg Engl 2010;92:258.

15. Day GA, Swanson CE, Hulcombe BG. Operative treatment of ankle fractures: a minimum ten-year follow-up. Foot Ankle Int 2001;22:102-6.

16. Phen HM, Schenker M. Minimizing posttraumatic osteoarthritis after high-energy intra-articular fracture. Orthop Clin North Am 2019;50:433-43.

17. Dabash S, Elabd A, Potter E, et al. Adding deltoid ligament repair in ankle fracture treatment: Is it necessary? A systematic review. Foot Ankle Surg 2019;25:714-20.

18. Michelson JD, Wright M, Blankstein M. Syndesmotic ankle fractures. 7 Orthop Trauma 2018;32:10-4.

19. Butler BA, Hempen EC, Barbosa M, et al. Deltoid ligament repair reduces and stabilizes the talus in unstable ankle fractures. 7 Orthop 2019;17:87-90.

20. Goetz JE, Davidson NP, Rudert MJ, et al. Biomechanical comparison of syndesmotic repair techniques during external rotation stress. Foot Ankle Int 2018;39:1345-54. 